\title{
Human decidual NK cells: unique and tightly regulated effector functions in healthy and pathogen-infected pregnancies
}

\author{
Philippe Le Bouteiller ${ }^{1,2,3}$ * \\ 1 Institut National de la Santé et de la Recherche Médicale, UMR 1043, Toulouse, France \\ ${ }^{2}$ Centre National de la Recherche Scientifique, UMR 5282, Toulouse, France \\ ${ }^{3}$ Centre de Physiopathologie Toulouse Purpan, Université Paul Sabatier, Toulouse, France
}

\section{Edited by:}

Simona Sivori, University of Genoa, Italy

\section{Reviewed by:}

Bojan Polic, University of Rijeka, Croatia

Sumati Rajagopalan, National Institutes of Health, USA

*Correspondence:

Philippe Le Bouteiller, Institut National de la Santé et de la Recherche Médicale, UMR 1043, Bat A, CHU Purpan, BP 3028, 31024 Toulouse Cedex 3, France e-mail:philippe.le-bouteiller@ inserm.fr
NK cells present in the peripheral blood (PB) respond rapidly to pathogens or pathogeninfected cells by various means including cytotoxicity and release of cytokines and chemokines. In addition they modulate adaptive immunity via the interaction with dendritic cells. Decidual NK cells (dNK) are poorly cytotoxic in healthy pregnancy, both in humans and rodents, when compared to their PB counterparts. We will discuss recent findings that may contribute to answer the following questions: (i) Do dNK possess functional killing machinery in normal healthy pregnancy? (ii) If so, what are the regulatory mechanisms that negatively control this effector function? (iii) Have dNK from early pregnant uterus the intrinsic ability to kill pathogen-infected autologous maternal uterine cells and/or produce soluble factors that stimulate the anti-pathogen adaptive immune response? (iv) Do dNK undergo a receptor repertoire profile shift when they are in contact with pathogen-infected uterine cells? (v) Which pathogen-mediated signal(s) and molecular interactions subvert the inhibition of dNK cytolytic activity?

Keywords: decidual NK cell, pregnancy, cytotoxicity, cytokine, angiogenic factors, cytomegalovirus, pathogens

\section{INTRODUCTION}

During the last decade, an increasing body of data based on genetic and functional studies have provided compelling evidence that during early healthy pregnancy, decidual NK (dNK) cells, the dominant lymphocyte population accumulated in the decidua basalis where the trophoblast cells infiltrate, exhibit unique functional and phenotypic characteristics (1-5). More than $95 \%$ of dNK are CD56 ${ }^{\text {bright }} \mathrm{CD} 16^{\text {neg }} \mathrm{CD} 160^{\text {neg }}$ (6). As opposed to $\mathrm{dNK}$, the major peripheral blood (PB)-NK cell subset is $\mathrm{CD} 56^{\mathrm{dim}} \mathrm{CD} 16^{+} \mathrm{CD} 160^{+}$, a specific phenotype associated with cytotoxic activity $(6,7)$. dNK cells express the two-domain killer immunoglobulin-like receptor (KIR) at higher frequency than PB-NK (8). This KIR2D repertoire is biased toward recognizing HLA-C, the dominant KIR ligand expressed by fetal extravillous trophoblast (8). PB-NK mostly contribute to the innate immunity against pathogen-infected or tumor cells by their cytolytic activity as well as release of proinflammatory cytokines and chemokines (9). In healthy pregnant uterus, dNK are poorly cytotoxic and have specialized pregnancyspecific functions, including a capacity to produce angiogenic molecules and to control trophoblast invasion (10-15). Until very recently (16), little information existed on the dNK capability of limiting local decidual pathogen infection.

\section{DECIDUAL NK CELLS PRODUCE SOLUBLE FACTORS THAT INFLUENCE PLACENTAL DEVELOPMENT IN NORMAL PREGNANCY}

Human dNK, in contrast with PB-NK, control two crucial functions in early healthy pregnancy. Firstly, dNK promote vascular growth in the decidua through the production of vascular endothelial growth factor (VEGF) and placental growth factor (PIGF) $(9,13,17-19)$ as well as of angiopoietin 1 , angiopoietin 2 , and TGF- $\beta 1(15,20)$. The release of these proangiogenic factors by dNK cells depends on the engagement of both NKp30 and NKp44 activating receptors by their specific ligands present on stromal decidual cells and extravillous trophoblast (17). Engagement of another NK cell receptor, KIR2DL4, by soluble HLA-G specific ligand was shown to induce the production of proangiogenic cytokines (21). Since KIR2DL4 is expressed by dNK either at the cell surface (22) or intracellularly (21), and soluble HLA$\mathrm{G}$ is secreted by trophoblast (23), this receptor-ligand couple is likely to contribute to the remodeling of the maternal vasculature in early pregnancy. The same authors have demonstrated that the KIR2DL4-induced senescence secretome of PB-NK can promote vascular remodeling and angiogenesis (24). Analysis of the dNK cell transcriptome revealed a strong similar senescence signature (24). Secondly, dNK release interleukin-8 (IL-8) and interferoninducible protein-10 (IP-10) chemokines that favor the migration of the extravillous cytotrophoblast into the decidua basalis by interacting with the CXCR3 and CXCR 1 receptors expressed by the trophoblast cells (17). Migration of extravillous trophoblast cells results in the invasion of spiral arteries thus contributing to the uterine vascular remodeling crucial for the placental development and outcome of pregnancy (25). Such production of chemoattractants by dNK is due to the engagement of NKp30 and NKp44 by their specific ligands expressed by trophoblast and stromal decidual cells (17). Similar interactions between dNK and trophoblast 
were observed in pregnant mouse, leading to mesometrial spiral artery remodeling (26-28). Activation of the KIR2DS1 dNK receptor by HLA-C2 was shown to produce the GM-CSF soluble factor, which enhanced migration of trophoblast (29). Other reports from our laboratory indicated that a specific engagement of NKp30 activating receptor on dNK induced the release of several soluble inflammatory and growth factors, including IFN- $\gamma$, TNF$\alpha$, MIP1- $\alpha$, MIP1- $\beta$, and GM-CSF $(22,30)$. During viral infection, these molecules are important to recruit and activate eosinophils, macrophages, and dendritic cells (31).

\section{DO DECIDUAL NK CELLS POSSESS FUNCTIONAL LYTIC MACHINERY IN NORMAL HEALTHY PREGNANCY?}

Human PB-NK are important innate immune effector cells that rapidly respond to and destroy malignant or virally infected cells (32). PB-NK kill infected cells via the polarized release of cytotoxic granules and the formation of immune synapse between the target cell and the PB-NK. The balance between activating and inhibitory NK cell receptor engagement upon recognition of specific cellular ligands determines the degree of NK cell activation or inactivation. In contrast to PB-NK, it has been demonstrated that both human $\mathrm{dNK}$ and mouse uterine NK cells displayed a poor ability to kill various classical NK cell targets $(12,28,33)$. dNK cells fail to polarize their microtubules organizing centers and perforin-containing granules to the synapse when they are in contact with HLA class I negative target cells (33). Although dNK cells fail to fully exert their lytic properties in normal pregnancy, they have lytic granules containing perforin, granzyme, and granulysin (34), indicating that they are potentially capable of cytolytic activity. Using redirected cell lysis assay, it has been shown that specific monoclonal antibody engagement of NKp46 activating receptor expressed on freshly isolated $\mathrm{dNK}$ induced intracellular calcium mobilization, granule exocytosis, and efficient P815 target cell lysis (22). It is of note that uterine NK cells in pregnant mice express the natural cytotoxicity receptor 1 (NCR1), an ortholog of human NKp46 also present in other species (35). This evolutionary conservation suggests that NKp46 could be involved in pathogen recognition (36). Experiments performed in mice homozygous for NCR1 loss revealed the role of NCR1 in the clearance of influenza virus infection (37). It has been demonstrated that granulysin release from mouse uterine NK cells in spontaneous abortion induced apoptosis of extravillous cytotrophoblast (28). All of these data strongly suggested that both human and mouse NK cells have the capability to exert a cytotoxic effector function in the pregnant uterus.

\section{WHAT ARE THE REGULATORY MECHANISMS THAT NEGATIVELY CONTROL THE CYTOTOXIC FUNCTION OF DECIDUAL NK CELLS IN NORMAL PREGNANCY?}

The importance of the balance between activating and inhibitory signals mediated by the specific engagement of activating and inhibitory NK cell receptors has been underlined by a number of reports (38). In addition to the inhibitory KIRs, three other $\mathrm{dNK}$ receptors play an inhibitory function, namely $2 \mathrm{~B} 4$, CD94/NKG2A, and LILRB1/ILT2. Whereas 2B4 was shown to be expressed on all $\mathrm{dNK}(22,39)$, both CD94/NKG2A and LILRB1/ILT2 are only present on a subset of $\mathrm{dNK}(8,12,22$,
33). Specific interaction between inhibitory dNK receptors and either MHC class Ia (HLA-C) or MHC class Ib molecules (HLAE, HLA-G) in human play an important role (40). We found that the co-engagement of CD94/NKG2A inhibitory receptor triggered a drastic inhibition of the cytolytic function of freshly isolated dNK from early decidua basalis (22). These results suggest that in situ the CD94/NKG2A receptor interaction with its HLA-E specific ligand expressed by trophoblast and other decidual cells is a dominant negative regulatory mechanism that likely prevents unwanted cytotoxicity toward non-infected fetalderived trophoblast cells. Another inhibitory mechanism depends on the engagement of the LILRB1/ILT2 dNK receptor by HLA-G which blocks dNK cytotoxicity $(41,42)$. It was also demonstrated that VEGF-C released by dNK in early pregnancy induced upregulation of TAP-1 in extravillous cytotrophoblast protecting them from cytolysis (13). Expression of the inhibitory form of 2B4 receptor on $\mathrm{dNK}$ also contributes to negatively regulate lytic function of dNK (39). Several regulatory mechanisms thus contribute to block the functional cytolytic machinery of $\mathrm{dNK}$ in normal pregnancy.

\section{HAVE DECIDUAL NK CELLS FROM EARLY PREGNANT UTERUS THE INTRINSIC ABILITY TO KILL PATHOGEN-INFECTED AUTOLOGOUS DECIDUAL CELLS AND PRODUCE SOLUBLE FACTORS THAT STIMULATE THE ANTI-PATHOGEN ADAPTIVE IMMUNE RESPONSE?}

A variety of pathogens, including human cytomegalovirus (hCMV) (10), human immunodeficiency virus 1 (HIV-1) (43), hepatitis C virus (44), toxoplasma (45), Plasmodium falciparum (46), bacteria in chorioamnionitis $(10,47)$ can infect the decidua basalis and potentially spread to the fetus through anchoring villi which are in contact with maternal blood of the intervillous space $(23,48)$. We will mainly focus on data dealing with hCMV which frequently infects decidua and has been detected in decidual stromal, macrophages, and endothelial cells (49). Areas of decidual hCMV infection were shown not to contain $\mathrm{T}$ cell accumulation, suggesting that, in addition to the humoral immunity (10), dNK could be another effector cell of the local anti-viral innate immunity preventing virus spread to the fetus. This hypothesis was recently validated by the observation that on biopsies of placental samples from hCMV termination, dNK have been identified in the vicinity of hCMV positive cells (16).

\section{DECIDUAL NK CELLS FULLY EXERT THEIR KILLING EFFECTOR FUNCTION WHEN IN CONTACT WITH hCMV-INFECTED AUTOLOGOUS DECIDUAL FIBROBLASTS}

A recent report from our lab has demonstrated that dNK play a role in the control of decidual cell hCMV infection (16). When exposed to hCMV-infected decidual autologous fibroblasts, a cell type abundantly present in decidual tissue, $\mathrm{dNK}$ acquires major functional and phenotypic changes (16). As opposed to dNK cells in contact to uninfected autologous decidual fibroblast, dNK cells engage immune synapse with hCMV-infected autologous stromal cells, polarize their lytic machinery toward infected target cells and efficiently kill them (16). Thus, the co-culture of dNK from early gestation with infected autologous decidual cells clearly enhances their cytotoxic ability. 
DECIDUAL NK CELLS MODULATE THEIR CYTOKINE AND CHEMOKINES PRODUCTION WHEN IN CONTACT WITH hCMV- OR HIV-1-INFECTED DECIDUAL FIBROBLASTS

Co-culture of dNK from early gestation with hCMV-infected autologous fibroblast induced a significant increased secretion of VEGF-A, sICAM, CXCL-1, IL-6, Granzyme-B, and MCP-1 by comparison with $\mathrm{dNK}$ in contact with uninfected similar target cells (16). IL-6 is a multifunctional cytokine that includes directing $\mathrm{T}$ cells differentiation in adaptive immunity (50). Although the first trimester pregnancy decidua is permissive to HIV-1 infection in vitro, the frequency of early in utero mother-to-child transmission of HIV-1 is low, suggesting efficient inhibitory regulatory mechanisms (51). dNK secrete cytokines and chemokines known to inhibit HIV-1 infection like CCL-3 and CCL4 or CXCL-12 (51). The killing of HIV-1-infected decidual cells by $\mathrm{dNK}$ could be mediated by specific engagement of NK cell receptors but also by induction of apoptosis mediated by the Fas/FasL pathway (51) as $\mathrm{dNK}$ were shown to produce FasL (52).

\section{DO DECIDUAL NK CELLS UNDERGO A RECEPTOR REPERTOIRE PROFILE SHIFT WHEN THEY ARE IN CONTACT WITH PATHOGEN-INFECTED UTERINE CELLS?}

hCMV infection modulates $\mathrm{dNK}$ cell receptor repertoire ability to kill virally infected decidual cells. Such a killing requires interaction between dNK cell activating receptors and specific ligands expressed at the cell surface of autologous decidual infected cells. Co-culture of $\mathrm{dNK}$ for $48 \mathrm{~h}$ with hCMV-infected decidual fibroblasts and without addition of IL-2 or IL-15, significantly increased the number of CD56 ${ }^{\mathrm{dim}} \mathrm{dNK}$, associated with appearance of CD16 (16). This dNK phenotype is consistent with acquisition of a cytotoxic profile (16). A recent study similarly reported a significant increase of the $\mathrm{CD} 56^{\mathrm{dim}} \mathrm{CD} 16^{+} \mathrm{dNK}$ subpopulation as early as $12 \mathrm{~h}$ after in vitro infection with Toxoplasma when compared to uninfected dNK (53). Furthermore, hCMV infection induced increased levels of expression of NKp44 and NKG2C receptors (16). Another study found that hCMV infection promoted a persistent expansion of PB-NK cells that express the CD94/NKG2C activating receptor (54). It is of note that the CD94NKG2 system is highly conserved in both rodents and primates (55), highlighting the critical activating function of this receptor/ligand couple. No change of NKp30 expression was noticed on dNK cells after contact with hCMV-infected fibroblast (16). When comparison was made between $\mathrm{dNK}$ and $\mathrm{PB}-\mathrm{NK}$, no significant change was observed in the expression of PB-NK cell repertoire after contact with hCMV-infected cells (16).

Disappearance of the NKp46 $6^{\text {high }} \mathrm{dNK}$ subset and decrease of KIR2DL1, KIR2DL4, and LILRB1/ILT2 expression were also observed on dNK in contact with hCMV-infected decidual fibroblasts (16). Thus, exposure to hCMV-infected cells modulates dNK receptor repertoire. An up-regulation of the NKG2D activating

Table 1 | Decidual NK receptor-ligands interactions, signals and cytotoxic effector functions.

\begin{tabular}{|c|c|c|c|c|c|}
\hline dNK co-culture with & dNK CD56 marker & dNK receptors & $\begin{array}{l}\text { Decidual fibroblast } \\
\text { ligands (L) }\end{array}$ & $\begin{array}{l}\text { dNK cytotoxic } \\
\text { signals }\end{array}$ & $\begin{array}{l}\text { dNK cytotoxic } \\
\text { effector function }\end{array}$ \\
\hline \multirow[t]{11}{*}{ Uninfected decidual fibroblasts } & CD56 $6^{\text {bright }} \sim 95 \%$ & CD94/NKG2A ${ }^{b}$ & HLA-E & Negative & NO \\
\hline & $\mathrm{CD} 56^{\mathrm{dim}} \leq 5 \%$ & $\mathrm{KIR} 2 \mathrm{DL} 1^{\mathrm{b}}$ & HLA-C & Negative & \\
\hline & & ILT2 $^{\mathrm{b}}$ & HLA-Gd & Negative & \\
\hline & & $2 \mathrm{~B} 4^{\mathrm{a}}$ & & Negative & \\
\hline & & NKG2DC & NKG2D-L: high level & Negative & \\
\hline & & CD94/NKG2C & NKG2C-L & $?$ & \\
\hline & & $\mathrm{KIR} 2 \mathrm{DL} 4^{\mathrm{b}}$ & HLA-Gd & $?$ & \\
\hline & & NKp30a & NKp30-L: low level & No signal & \\
\hline & & $\mathrm{NKp} 44^{\mathrm{a}}$ & NKp44-L: high level & No signal & \\
\hline & & NKp46 & NKp46-L: low level & No signal & \\
\hline & & CD16 ${ }^{\text {neg }}$ & & & \\
\hline \multirow[t]{10}{*}{ hCMV-infected decidual fibroblasts } & CD56 $6^{\text {bright }} \sim 48 \%$ & CD94/NKG2A: down & HLA-E: down & $?$ & YES \\
\hline & $\mathrm{CD}^{\mathrm{dim}} \sim 40 \%$ & KIR2DL1: down & HLA-C & $?$ & \\
\hline & & ILT2: down & HLA-G ${ }^{d}$ & $?$ & \\
\hline & & $N K G 2 D^{C}$ & NKG2D-L: down & Positive & \\
\hline & & CD94/NKG2C: up & HLA-E: down & Positive & \\
\hline & & KIR2DL4: down & $H L A-G^{d}$ & $?$ & \\
\hline & & NKp30a & NKp30-L: up & No signal & \\
\hline & & NKp46: down & NKp46-L & No signal & \\
\hline & & NKp44: up & NKp44-L: down & Negative & \\
\hline & & CD16 ${ }^{b}$ & & & \\
\hline
\end{tabular}

20-40\% positive cells.

${ }^{b} 50-80 \%$ positive cells.

c $100 \%$ positive cells (flow cytometry).

${ }^{a} H L A-G$ is expressed on extravillous cytotrophoblast present among decidual adherent cells. 
receptor expression was reported in Toxoplasma-infected dNK which correlated with enhanced cytolytic activity against human extravillous cytotrophoblast target cells (53). Based on these data, infection of decidua by other pathogens is likely to trigger a change in the repertoire profile of $\mathrm{dNK}$ receptors.

\section{WHICH PATHOGEN-MEDIATED SIGNAL(S) AND MOLECULAR INTERACTIONS SUBVERT THE INHIBITION OF DECIDUAL NK CELL CYTOLYTIC ACTIVITY?}

Using Fc-chimeric proteins, we found that hCMV infection of decidual fibroblast modulated the expression of several NKR ligands: NKp30L and NKG2DL were significantly increased whereas NKp44L and NKp46L decreased (16). Blocking the engagement of NKp44 with its specific ligand resulted in an increase killing of infected autologous fibroblast by dNK cells, suggesting the presence of an inhibitory form of NKp44. In contrast, blocking NKG2D ligation induced a decrease of dNK cytotoxicity. These observations suggested a crucial role of NKG2D-mediated cytotoxic function of dNK against hCMV-infected fibroblasts. Infection of decidual fibroblast resulted in a diminishment of HLA-E expression on their cell surface. Blockade of HLA-E ligation with its specific dNK cell receptor induced a decrease of dNK killing, suggesting that HLA-E on hCMV-infected autologous fibroblasts did bind the CD94/NKG2C activating receptor. In contrast, neither NKp46 nor NKp30 seemed to be implicated in dNK cell lytic response. dNK cell subset that expresses the LILRB1/ILT2 receptor could be involved in the control of HIV-1 infection as it has been demonstrated in the PB-NK counterpart (56).

All of these data, including those dealing with hCMV infection and summarized in Table 1, showed that pathogen-mediated signals (i.e., modulation of expression of dNK receptor-ligands systems) and molecular interactions (engagement of dNK receptors with specific pathogen-mediated ligands) contribute to subvert the inhibition of $\mathrm{dNK}$ cell cytotoxic activity observed in normal pregnancy.

\section{CONCLUSION}

Instead of being detrimental, dNK cells have positive effects in healthy human pregnancy as they promote placental development through the crucial release of angiogenic factors and attraction of extravillous trophoblast. After contact with hCMV-infected autologous decidual fibroblasts, dNK acquire cytotoxic capacity by subverting their killing inhibitory regulatory mechanisms occurring in normal pregnancy. Effector functions of $\mathrm{dNK}$ in pathogen-infected pregnancy require engagement of shifted repertoire of activating and/or inhibiting dNK cell receptors by specific ligands up- or down-regulated in pathogen-infected decidual cells, including HLA-E and NKG2DL. These results, if confirmed by further studies dealing with different viruses or pathogens, strongly suggest that, in situ, dNK are likely to contribute to local pathogen innate immune control and clearance during the initial phase of decidua infection.

\section{ACKNOWLEDGMENTS}

Work by the author and his team has been supported by INSERM, CNRS, Toulouse III University, and the European Network of Excellence on Embryo implantation control (EMBIC).

\section{REFERENCES}

1. Manaster I, Mandelboim O. The unique properties of human NK cells in the uterine mucosa. Placenta (2008) 29(Suppl A):S60-6. doi:10.1016/j.placenta. 2007.10.006

2. Koopman L, Kopcow H, Rybalov B, Boyson J, Orange J, Schatz F, et al. Human decidual natural killer cells are a unique NK cell subset with immunomodulatory potential. J Exp Med (2003) 198:1201-12. doi:10.1084/jem.20030305

3. Bulmer JN, Williams PJ, Lash GE. Immune cells in the placental bed. Int J Dev Biol (2010) 54:281-94. doi:10.1387/ijdb.082763jb

4. Moffett-King A. Natural killer cells and pregnancy. Nat Rev Immunol (2002) 2:656-63. doi:10.1038/nri886

5. Tabiasco J, Rabot M, Aguerre-Girr M, El Costa H, Berrebi A, Parant O, et al. Human decidual NK cells: unique phenotype and functional properties - a review. Placenta (2006) 27(Suppl A):S34-9. doi:10.1016/j.placenta.2006.01.009

6. Le Bouteiller P, Tabiasco J, Polgar B, Kozma N, Giustiniani J, Siewiera J, et al. CD160: a unique activating NK cell receptor. Immunol Lett (2011) 138:170-5. doi:10.1016/j.imlet.2011.02.003

7. Le Bouteiller P, Barakonyi A, Giustiniani J, Lenfant F, Marie-Cardine A, AguerreGirr M, et al. Engagement of CD160 receptor by HLA-C is a triggering mechanism used by circulating natural killer (NK) cells to mediate cytotoxicity. Proc Natl Acad Sci U S A (2002) 99:16963-8. doi:10.1073/pnas.012681099

8. Male V, Sharkey A, Masters L, Kennedy PR, Farrell LE, Moffett A. The effect of pregnancy on uterine NK cell KIR repertoire. Eur J Immunol (2011) 41:1-11. doi:10.1002/eji.201141445

9. Vacca P, Mingari M, Moretta L. Natural killer cells in human pregnancy. J Reprod Immunol (2013) 97:14-9. doi:10.1016/j.jri.2012.10.008

10. Erlebacher A. Immunology of the maternal-fetal interface. Annu Rev Immunol (2013) 31:387-411. doi:10.1146/annurev-immunol-032712-100003

11. Quenby S, Nik H, Innes B, Lash G, Turner M, Drury J, et al. Uterine natural killer cells and angiogenesis in recurrent reproductive failure. Hum Reprod (2009) 24:45-54. doi:10.1093/humrep/den348

12. Vacca P, Moretta L, Moretta A, Mingari MC. Origin, phenotype and function of human natural killer cells in pregnancy. Trends Immunol (2011) 32:517-23. doi:10.1016/j.it.2011.06.013

13. Kalkunte SS, Mselle TF, Norris WE, Wira CR, Sentman CL, Sharma S. Vascular endothelial growth factor $\mathrm{C}$ facilitates immune tolerance and endovascular activity of human uterine NK cells at the maternal-fetal interface. J Immunol (2009) 182:4085-92. doi:10.4049/jimmunol.0803769

14. Croy BA, Esadeg S, Chantakru S, van den Heuvel M, Paffaro VA, He H, et al. Update on pathways regulating the activation of uterine natural killer cells, their interactions with decidual spiral arteries and homing of their precursors to the uterus. J Reprod Immunol (2003) 59:175-91. doi:10.1016/S0165-0378(03) 00046-9

15. Cerdeira AS, Rajakumar A, Royle C, Lo A, Husain Z, Thadhani RI, et al. Conversion of peripheral blood NK cells to a decidual NK-like phenotype by a cocktail of defined factors. J Immunol (2013) 190:3939-48. doi:10.4049/ jimmunol.1202582

16. Siewiera J, El Costa H, Tabiasco J, Berrebi A, Cartron G, Le Bouteiller P, et al. Human cytomegalovirus infection elicits new decidual natural killer cell effector function. PLoS Pathog (2013) 9:e1003257. doi:10.1371/journal.ppat.1003257

17. Hanna J, Goldman-Wohl D, Hamani Y, Avraham I, Greenfield C, NatansonYaron S, et al. Decidual NK cells regulate key developmental processes at the human fetal-maternal interface. Nat Med (2006) 12:1065-74. doi:10.1038/ $\mathrm{nm} 1452$

18. Lash GE, Robson SC, Bulmer JN. Review: functional role of uterine natural killer (uNK) cells in human early pregnancy decidua. Placenta (2010) 31(Suppl):S87-92. doi:10.1016/j.placenta.2009.12.022

19. Lippe EMO, Yamada AT, Sharma S. Human uterine natural killer cell: friends or foes of pregnancy outcome. In: Chaouat G, Sandra O, Lédée N editors. Immunology of Pregnancy 2013. Sharjah: Bentham Science Publishers (2013). p. 360-76.

20. Lash GE, Schiessl B, Kirkley M, Innes BA, Cooper A, Searle RF, et al. Expression of angiogenic growth factors by uterine natural killer cells during early pregnancy. J Leukoc Biol (2006) 80:572-80. doi:10.1189/jlb.0406250

21. Rajagopalan S, Bryceson YT, Kuppusamy SP, Geraghty DE, van der Meer A, Joosten I, et al. Activation of NK cells by an endocytosed receptor for soluble HLA-G. PLoS Biol (2006) 4:e9. doi:10.1371/journal.pbio.0040009

22. El Costa H, Casemayou A, Aguerre-Girr M, Rabot M, Berrebi A, Parant O, et al. Critical and differential roles of NKp46- and NKp30-activating receptors expressed by uterine NK cells in early pregnancy. J Immunol (2008) 181:3009-17. 
23. Le Bouteiller P, Solier C, Pröll J, Aguerre-Girr M, Fournel S, Lenfant F. Placental HLA-G protein expression in vivo: where and what for? Hum Reprod Update (1999) 5:223-33. doi:10.1093/humupd/5.3.223

24. Rajagopalan S, Long EO. Cellular senescence induced by CD158d reprograms natural killer cells to promote vascular remodeling. Proc Natl Acad Sci U S A (2012) 109:20596-601. doi:10.1073/pnas.1208248109

25. Pijnenborg R. Manipulating human reproduction: a retrospective view on Aldous Huxley's Brave New World. Gynecol Obstet Invest (2006) 61:149-54. doi:10.1159/000090627

26. Madeja Z, Yadi H, Apps R, Boulenouar S, Roper SJ, Gardner L, et al. From the cover: paternal MHC expression on mouse trophoblast affects uterine vascularization and fetal growth. Proc Natl Acad Sci U S A (2011) 108:4012-7. doi:10.1073/pnas.1005342108

27. Croy BA, Chantakru S, Esadeg S, Ashkar AA, Wei Q. Decidual natural killer cells: key regulators of placental development (a review). J Reprod Immunol (2002) 57:151-68. doi:10.1016/S0165-0378(02)00005-0

28. Lima PDA, Paffaro VA Jr, Yamada AT. Functional duality of mouse uterine natural killer cell in pregnancy. In: Chaouat G, Sandra O, Lédée N editors. Immunology of Pregnancy 2013. Sharjah: Bentham Science Publishers (2013). p. 335-58.

29. Xiong S, Sharkey AM, Kennedy PR, Gardner L, Farrell LE, Chazara O, et al. Maternal uterine NK cell-activating receptor KIR2DS1 enhances placentation. J Clin Invest (2013) 123:4264-72. doi:10.1172/JCI68991

30. El Costa H, Tabiasco J, Berrebi A, Parant O, Aguerre-Girr M, Piccinni MP, et al. Effector functions of human decidual NK cells in healthy early pregnancy are dependent on the specific engagement of natural cytotoxicity receptors. JReprod Immunol (2009) 82:142-7. doi:10.1016/j.jri.2009.06.123

31. Salazar-Mather TP, Hamilton TA, Biron CA. A chemokine-to-cytokine-tochemokine cascade critical in antiviral defense. J Clin Invest (2000) 105:985-93. doi:10.1172/JCI9232

32. Jost S, Altfeld M. Control of human viral infections by natural killer cells. Annu Rev Immunol (2013) 31:163-94. doi:10.1146/annurev-immunol-032712100001

33. Kopcow HD, Allan DS, Chen X, Rybalov B, Andzelm MM, Ge B, et al. Human decidual NK cells form immature activating synapses and are not cytotoxic. Proc Natl Acad Sci U S A (2005) 102:15563-8. doi:10.1073/pnas.0507835102

34. Veljkovic Vujaklija D, Dominovic M, Gulic T, Mahmutefendic H, Haller H, Saito S, et al. Granulysin expression and the interplay of granulysin and perforin at the maternal-fetal interface. J Reprod Immunol (2013) 97:186-96. doi:10.1016/j.jri.2012.11.003

35. Yadi H, Burke S, Madeja Z, Hemberger M, Moffett A, Colucci F. Unique receptor repertoire in mouse uterine NK cells. J Immunol (2008) 181:6140-7.

36. Koch J, Steinle A, Watzl C, Mandelboim O. Activating natural cytotoxicity receptors of natural killer cells in cancer and infection. Trends Immunol (2013) 34:182-91. doi:10.1016/j.it.2013.01.003

37. Gazit R, Gruda R, Elboim M, Arnon TI, Katz G, Achdout H. Lethal influenza infection in the absence of the natural killer cell receptor gene Ncr1. Nat Immunol (2006) 7:517-23. doi:10.1038/ni1322

38. Vivier E, Raulet DH, Moretta A, Caligiuri MA, Zitvogel L, Lanier LL, et al. Innate or adaptive immunity? The example of natural killer cells. Science (2011) 331:44-9. doi:10.1126/science.1198687

39. Vacca P, Pietra G, Falco M, Romeo E, Bottino C, Bellora F, et al. Analysis of natural killer cells isolated from human decidua: evidence that 2B4 (CD244) functions as an inhibitory receptor and blocks NK-cell function. Blood (2006) 108:4078-85. doi:10.1182/blood-2006-04-017343

40. Le Bouteiller P. MHC antigen expression/function at the embryonic interface. Part A: major histocompatibility complex class I unique expression in human trophoblast: facts, questions and controversies. In: Chaouat G, Sandra O, Lédée $\mathrm{N}$ editors. Immunology of Pregnancy 2013. Sharjah: Bentham Science Publishers (2013).p. 158-73.

41. Favier B, Lemaoult J, Lesport E, Carosella ED. ILT2/HLA-G interaction impairs NK-cell functions through the inhibition of the late but not the early events of the NK-cell activating synapse. FASEB J (2010) 24:689-99. doi:10.1096/fj.09135194

42. Navarro F, Llano M, Bellon T, Colonna M, Geraghty DE, Lopez-Botet M. The ILT2(LIR1) and CD94/NKG2A NK cell receptors respectively recognize HLA-G1 and HLA-E molecules co-expressed on target cells.
Eur J Immunol (1999) 29:277-83. doi:10.1002/(SICI)1521-4141(199901)29: 01<277::AID-IMMU277>3.0.CO;2-4

43. Marlin R, Nugeyre MT, Duriez M, Cannou C, Le Breton A, Berkane N, et al. Decidual soluble factors participate in the control of HIV-1 infection at the maternofetal interface. Retrovirology (2011) 8:58. doi:10.1186/1742-4690-8-58

44. Hurtado CW, Golden-Mason L, Brocato M, Krull M, Narkewicz MR, Rosen $\mathrm{HR}$, et al. Innate immune function in placenta and cord blood of hepatitis C - seropositive mother-infant dyads. PLoS One (2010) 5:e12232. doi:10.1371/ journal.pone.0012232

45. Nigro G, Piazze J, Paesano R, Mango T, Provvedi S, Capuano O, et al. Low levels of natural killer cells in pregnant women transmitting Toxoplasma gondii. Prenat Diagn (1999) 19:401-4. doi:10.1002/(SICI)1097-0223(199905)19:5<401::AIDPD559>3.0.CO;2-X

46. Sartelet H, Schleiermacher D, Le-Hesran JY, Graesslin O, Gaillard D, Fe M, et al. Less HLA-G expression in Plasmodium falciparum-infected third trimester placentas is associated with more natural killer cells. Placenta (2005) 26:505-11. doi:10.1016/j.placenta.2004.08.006

47. Riley JK. Trophoblast immune receptors in maternal-fetal tolerance. Immunol Invest (2008) 37:395-426. doi:10.1080/08820130802206066

48. Moffett A, Loke C. Immunology of placentation in eutherian mammals. Nat Rev Immunol (2006) 6:584-94. doi:10.1038/nri1897

49. Pereira L, Maidji E, McDonagh S, Tabata T. Insights into viral transmission at the uterine-placental interface. Trends Microbiol (2005) 13:164-74. doi:10.1016/j.tim.2005.02.009

50. Prins J, Gomez-Lopez N, Robertson S. Interleukin-6 in pregnancy and gestational disorder. J Reprod Immunol (2012) 95:1-14. doi:10.1016/j.jri.2012.05.004

51. Quillay H, Marlin R, Duriez M, Nugeyre MT, Menu E. The control of HIV-1 in utero transmission at the materno-fetal interface by immunological determinants. In: Chaouat G, Sandra O, Lédée N editors. Immunology of Pregnancy 2013. Sharjah: Bentham Science Publishers (2013). p. 827-55.

52. Crncic TB, Laskarin G, Frankovic KJ, Tokmadzic VS, Strbo N, Bedenicki I, et al. Early pregnancy decidual lymphocytes beside perforin use Fas ligand (FasL) mediated cytotoxicity. J Reprod Immunol (2007) 73:108-17. doi:10.1016/j.jri. 2006.07.001

53. Xu X, Fu Q, Zhang Q, Zhao M, Gao Z, Liu X, et al. Changes of human decidual natural killer cells cocultured with YFP-Toxoplasma gondii: implications for abnormal pregnancy. Fertil Steril (2013) 99:427-32. doi:10.1016/j.fertnstert. 2012.09.016

54. Muntasell A, ópez-Montañés ML, Vera A, Heredia G, Romo N, Peñafiel J, et al. NKG2C zygosity influences CD94/NKG2C receptor function and the NK-cell compartment redistribution in response to human cytomegalovirus. Eur J Immunol (2013). doi:10.1002/eji.201343773. [Epub ahead of print].

55. Fang M, Orr MT, Spee P, Egebjerg T, Lanier LL, Sigal LJ. CD94 is essential for NK cell-mediated resistance to a lethal viral disease. Immunity (2011) 34:579-89. doi:10.1016/j.immuni.2011.02.015

56. Scott-Algara D, Arnold V, Didier C, Kattan T, Pirozzi G, Barre-Sinoussi F, et al. The CD85j+ NK cell subset potently controls HIV-1 replication in autologous dendritic cells. PLoS One (2008) 3:e1975. doi:10.1371/journal.pone.0001975

Conflict of Interest Statement: The author declares that the research was conducted in the absence of any commercial or financial relationships that could be construed as a potential conflict of interest.

Received: 08 October 2013; accepted: 08 November 2013; published online: 25 November 2013.

Citation: Le Bouteiller P (2013) Human decidual NK cells: unique and tightly regulated effector functions in healthy and pathogen-infected pregnancies. Front. Immunol. 4:404. doi: 10.3389/fimmu.2013.00404

This article was submitted to NK Cell Biology, a section of the journal Frontiers in Immunology.

Copyright (C) 2013 Le Bouteiller. This is an open-access article distributed under the terms of the Creative Commons Attribution License (CC BY). The use, distribution or reproduction in other forums is permitted, provided the original author(s) or licensor are credited and that the original publication in this journal is cited, in accordance with accepted academic practice. No use, distribution or reproduction is permitted which does not comply with these terms. 